\title{
Effect of acute hypobaric hypoxia on the endothelial glycocalyx and digital reactive hyperemia in humans
}

\author{
Pär I. Johansson 1,2, Anita Bergström ${ }^{3}$, Niels J. Aachmann-Andersen ${ }^{4}$, Martin A. S. Meyer ${ }^{1}$, \\ Sisse R. Ostrowski ${ }^{1}$, Nikolai B. Nordsborg ${ }^{5}$ and Niels V. Olsen ${ }^{3,4 *}$ \\ ${ }^{1}$ Section for Transfusion Medicine, Capital Region Blood Bank, The Diagnostic Centre, Copenhagen University Hospital (Rigshospitalet), Copenhagen, Denmark \\ 2 Department of Surgery, University of Texas Medical School, Houston, TX, USA \\ ${ }^{3}$ Department of Neuroanaesthesia, The Neuroscience Centre, Copenhagen University Hospital (Rigshospitalet), Copenhagen, Denmark \\ ${ }^{4}$ BrainLab, Department of Neuroscience and Pharmacology, University of Copenhagen, Copenhagen, Denmark \\ ${ }^{5}$ Department of Nutrition, Exercise and Sport, University of Copenhagen, Copenhagen, Denmark
}

\section{Edited by:}

Gaetano Santulli, Columbia

University Medical Center, USA

Reviewed by:

Celena Scheede-Bergdahl, McGill

University, Canada

Andreas Bergdahl, Concordia

University, Canada

\section{*Correspondence:}

Niels V. Olsen, Department of

Neuroanaesthesia, The

Neuroscience Centre, Copenhagen

University Hospital (Rigshospitalet),

9 Blegdamsvej,

DK-2100 Copenhagen, Denmark

e-mail:nvolsen@sund.ku.dk
Introduction: Hypoxia is associated with increased capillary permeability. This study tested whether acute hypobaric hypoxia involves degradation of the endothelial glycocalyx.

Methods: We exposed 12 subjects to acute hypobaric hypoxia (equivalent to $4500 \mathrm{~m}$ for 2-4h) and measured venous blood concentrations of biomarkers reflecting endothelial and glycocalyx degradation (catecholamines, syndecan-1, soluble CD40 ligand, protein C, soluble thrombomodulin, tissue-type plasminogen activators, histone-complexed DNA fragments, and nitrite/nitrate). Endothelial function was assessed by the hyperemic response to brachial artery occlusion by peripheral arterial tonometry.

Results: Compared with normoxic baseline levels, hypoxia increased concentrations of syndecan-1 from 22 (95\% confidence interval: $17-27)$ to $25(19-30) \mathrm{ng} / \mathrm{ml}(p<0.02)$ and protein C from $76(70-83) \%$ to $81(74-88) \%(p<0.02)$. Nitrite/nitrate decreased from $23(18-27) \mu \mathrm{M}$ at baseline to $19(14-24) \mu \mathrm{M}$ and 18 (14-21) $\mu \mathrm{M}$ in hypoxia and recovery, respectively $(p<0.05)$. Other biomarkers remained unchanged. The post-occlusion/pre-occlusion ratio (reactive hyperemia index, $\mathrm{RHI}$ ) decreased from 1.80 (1.52-2.07) in normoxia to $1.62(1.28-1.96)$ after $2-4 \mathrm{~h}$ of hypobaric hypoxia and thereafter increased to $2.43(1.99-2.86)$ during normoxic recovery $(p<0.01)$.

Conclusions: The increase in syndecan-1 and protein $C$ suggests that acute hypobaric hypoxia produces a minor degree of glycocalyx degradation and overall cellular damage. After hypoxia $\mathrm{RHI}$ rebounded to higher than baseline levels suggesting improved endothelial functionality.

Keywords: endothelium, hypoxia, glycocalyx, nitrite/nitrate, peripheral arterial tonometry, protein C, syndecan-1

\section{INTRODUCTION}

Acute hypoxia rapidly activates endothelial cells leading to increased vascular permeability and initiation of prothrombotic and inflammatory reactions (Ten and Pinsky, 2002; Gonzalez and Wood, 2010). Hypoxic exposure may also result in endotheliumdependent vasoconstriction, both by release of endothelialderived substances including endothelins, superoxide anions and thromboxane $\mathrm{A}_{2}$, and by a decrease in nitric oxide bioavailability (Schneider et al., 2001; Ten and Pinsky, 2002; Bärtsch et al., 2005; Gonzalez and Wood, 2010). In subjects susceptible to high altitude pulmonary edema (HAPE), strong evidence exists to suggest that impairment of systemic endothelial function is a main cause of enhanced hypoxic pulmonary vasoconstriction in these subjects (Busch et al., 2001; Swenson et al., 2002; Berger et al., 2005).

The luminal side of the endothelium is lined by the glycocalyx consisting of a $0.2-1 \mu \mathrm{m}$ thick negatively charged, antiadhesive and anticoagulant carbohydrate-rich layer which protects the endothelium and contributes to its barrier function (Pries et al., 2000; Johansson et al., 2011). Degradation of the glycocalyx results in local thrombin formation, fibrinolysis, and adhesion of platelets and leucocytes (Vink et al., 2000; Nieuwdorp et al., 2006; Chappell et al., 2010). In trauma patients and patients with acute myocardial infarction, high levels of circulating syndecan1, a transmembrane endothelial proteoglycan and a marker of endothelial glycocalyx degradation (Pries et al., 2000), is associated with inflammation, coagulopathy, and increased mortality (Johansson et al., 2011; Ostrowski et al., 2013a,b). Acute exposure to hypoxia may occur in high altitude and aviation activities and also acute oxygen deprivation encompasses several clinical modalities such as smoke intoxication, respiratory distress syndrome, pulmonary and cardiac thromboembolism, sepsis, and trauma. In this study, we evaluated whether exposure to shortterm, acute hypobaric hypoxia is associated with degradation of 
the endothelial glycocalyx. The effect of short-term hypoxia per se was studied in healthy subject by the use of a low-pressure chamber. The response of endothelial cells to shear stress was assessed by digital pulse amplitude tonometry (Faizi et al., 2009; Hamburg and Benjamin, 2009; Hedetoft and Olsen, 2014).

\section{MATERIALS AND METHODS SUBJECTS AND EXPERIMENTAL PROTOCOL}

Twelve healthy males aged 25 (20-29) years (mean and range), height $181(173-189) \mathrm{cm}$ and body mass index $22(18-26) \mathrm{kg} / \mathrm{m}^{2}$ entered the study after having given their written, informed consent. The study was approved by the Regional Ethical Committee of the Copenhagen Region, 2 Kongens Vaenge, DK-3400 Hillerød, Denmark, E-mail: regionh@regionh.dk (J.No. H-4-2011-080). All subjects were non-smokers living at sea level and free of disease and medication. After an overnight fast, the subjects arrived to the laboratory at 08.00 a.m. The subjects abstained from heavy physical exercise and alcohol intake in the preceding $24 \mathrm{~h}$. Drinking water was provided freely during the experiment. The experiment was conducted inside a low-pressure chamber with four subjects in each session. After insertion of an intravenous catheter in a cubital vein, the subjects rested for at least $1 \mathrm{~h}$ in a sitting position that was maintained throughout the study period. Thereafter, baseline measurements by digital pulse amplitude tonometry and blood samples were obtained in normobaric normoxia (open chamber). The chamber was then decompressed (over $15-20 \mathrm{~min}$ ) to a simulated altitude af $4500 \mathrm{~m}$ above sea level. This decompression produces a hypobaric hypoxia comparable to that obtained in high altitude laboratories (Pikes Peak, Colarado, USA; Regina Margherita Hut, Monte Rosa, Italy; and l'Observatoire Vallot, Mont Blanc, France). In each session, measurements in the four subjects, in succession one by one, were conducted within 2$4 \mathrm{~h}$ in hypobaric hypoxia. Finally, measurements were repeated in the recovery period $1-3 \mathrm{~h}$ after re-compression to ambient normoxic conditions. At the same time points heart rate and arterial pressure were measured and arterial blood was sampled for analysis of $\mathrm{SaO}_{2}, \mathrm{PaCO}_{2}, \mathrm{PaO}_{2}$, and $\mathrm{pH}$, and concentrations of hemoglobin, glucose, and lactate by the use of a Radiometer ABL 725 device (Radiometer Medical A/S, Copenhagen, Denmark).

\section{ENZYME LINKED IMMUNOSORBENT ASSAY (ELISA) MEASUREMENTS}

Soluble biomarkers of sympathoadrenal activation, endothelial cell and glycocalyx activation and damage, natural anticoagulation, fibrinolysis and platelet activation were measured at baseline, and again at recovery by commercially available immunoassays in plasma/serum according to the manufactures recommendations. Adrenaline and noradrenaline (sympathoadrenal activation) were measured in EDTA plasma by a 2-CAT ELISA, Labor Diagnostica Nord GmbH \& Co. KG, Nordhorn, Germany. Lower limits of detection (LLD) were $10 \mathrm{pg} / \mathrm{ml}$ (normal reference $<100 \mathrm{pg} / \mathrm{ml}$ ) and $50 \mathrm{pg} / \mathrm{ml}$ (normal reference $<600 \mathrm{pg} / \mathrm{ml}$ ), respectively. Histone-complexed DNA fragments (endothelial cell damage) in EDTA plasma were measured by a Cell Death Detection ELISAPLUS, Roche, Hvidovre, Denmark (LLD not stated, relative quantification). Soluble
CD40 ligand (pro-inflammatory activation) was determined by ELISA (sCD40L, R\&D Systems Europe; LLD $4.2 \mathrm{pg} / \mathrm{ml}$ ). Soluble thrombomodulin (natural anticoagulation) and Protein $C$ (endothelial cell damage) were measured in citrate plasma (sTM, Nordic Biosite, Copenhagen, Denmark, LLD $0.38 \mathrm{ng} / \mathrm{ml}$; and PC, Helena Laboratories, Beaumont, TX, US, LLD not stated, relative quantification). Tissue-type plasminogen activators (fibrinolysis and platelet activation) were measured in citrate plasma (tPA, ADI, detects sc-tPA, tc-tPA, and tPA/PAI1 complexes; LLD $1 \mathrm{ng} / \mathrm{ml}$ ). Syndecan-1 (glycocalyx activation and damage) was determined in serum (Diaclone SAS, Besancon, France; LLD $4.94 \mathrm{ng} / \mathrm{ml}$ ). Samples for measurement of nitrite/nitrate were spun through a $30-\mathrm{kD}$ micropore filter (Nanosep 30k Omega, Pall Corp., Ann Arbor, Michigan) prior to duplicate analysis with a commercially available NOx detection kit based on the Griess reaction (cat. 780001, Nitrite/Nitrate Colorimetric Assay Kit, Cayman Chemicals, Ann Arbor, Michigan).

\section{DIGITAL PULSE AMPLITUDE TONOMETRY}

We used an EndoPAT 2000 device (Itamar Medical Ltd., Caesarea, Israel) consisting of a fingertip plethysmograph (Faizi et al., 2009; Hamburg and Benjamin, 2009; Hedetoft and Olsen, 2014). The device includes two fingerprobes, each placed on a fingertip on each hand. These are used for parallel measurements and are connected to a computer. The probe consists of a rigid external cap around an air-filled chamber with a sensor. When the chamber is filled with air, a uniform pressure is provided which prevents the veno-arteriolar vasoconstrictive reflex. The probe detects changes in volume in relation to the arterial pulsation. A cuff was placed on the arm in which the measurement was performed. Measurements by the other probe served as a control. Each measurement consisted of three phases: baseline, occlusion and reactive hyperemia. For baseline measurements, the probe was set to inflate to $10 \mathrm{mmHg}$ below diastolic pressure. For occlusion, the test arm was occluded to suprasystolic pressure for $5 \mathrm{~min}$ (Faizi et al., 2009). The subsequent increase in blood flow leads to a flow-mediated dilatation, manifesting as reactive hyperemia, which was measured by the device as an increase in the pulse-signal amplitude. The EndoPAT software calculates a post-occlusion/pre-occlusions-ratio, the reactive hyperemia index (RHI). An RHI $\leq 1.67$ is described as being abnormal by the manufacturer (http://www.itamar-medical.com/images/ EndoPATMultiFunctionUSA.pdf).

\section{STATISTICAL ANALYSIS}

Statistical analysis was performed using IBM SPSS Statistics 20 (IBM SPSS Statistics, Armonk, NY). Values during hypoxia and in the post-hypoxic recovery period were compared with baseline by the use of paired $t$-tests. Correlations between EndoPAT RHI values and endothelial markers that had changed significantly during the experiment, and between RHI and NOx values, all at identical time points, were investigated by Pearson's and Spearman's correlation as well as linear and logarithmic regression (by curve estimation). A level of $P<0.05$ was considered statistical significant. Results are presented as means with $95 \%$ confidence intervals. 


\section{RESULTS}

Heart rate and mean arterial blood pressure remained unchanged (Table 1). $\mathrm{PaO}_{2}, \mathrm{PaCO}_{2}$ and $\mathrm{O}_{2}$ saturation decreased during hypoxia, whereas $\mathrm{pH}$ and lactate increased (Table 1); values were restored to baseline levels during the ensuing period of normoxia (recovery) with the exception of $\mathrm{PaCO}_{2}$ that remained lower than baseline levels (Table 1). Also plasma hemoglobin concentration at recovery was lower compared with baseline (Table 1). Venous plasma concentrations of nitrite/nitrate decreased during hypoxia compared with baseline, and remained at a similar level during recovery (Table $\mathbf{1}$ ).

Syndecan-1 and protein $\mathrm{C}$ increased from the baseline levels to the recovery levels (Table 2). Concentrations of adrenaline, noradrenaline, thrombomodulin, tissue-type plasminogen activators, plasminogen activator inhibitor 1, soluble CD40 ligand, and histone-complexed DNA fragments remained unchanged (Table 2).

Table 1 | Effect of hypobaric hypoxia.

\begin{tabular}{lccc}
\hline & Baseline & Hypoxia & Recovery \\
\hline Heart rate $\left(\mathrm{min}^{-1}\right)$ & $70(62-77)$ & $75(69-81)$ & $68(62-74)$ \\
$\mathrm{MABP}(\mathrm{mm} \mathrm{Hg})$ & $90(85-95)$ & $83(76-90)$ & $84(77-90)$ \\
$\mathrm{pH}$ & $7.40(7.39-7.41)$ & $7.47(7.46-7.49)^{*}$ & $7.42(7.39-7.45)$ \\
$\mathrm{PaO}_{2}(\mathrm{~mm} \mathrm{Hg})$ & $103(99-107)$ & $43(39-46)^{*}$ & $102(98-106)$ \\
$\mathrm{P}_{\mathrm{aCO}}(\mathrm{mm} \mathrm{Hg})$ & $40(38-42)$ & $32(30-35)^{*}$ & $36(34-37)^{*}$ \\
$\mathrm{~S}_{\mathrm{a}} \mathrm{O}_{2}(\%)$ & $98(98-98)$ & $81(77-85)^{*}$ & $99(98-99)$ \\
$\mathrm{Hgb}_{(\mathrm{mM})}$ & $9.8(9.1-10.4)$ & $9.3(9.0-9.6)$ & $9.2(8.8-9.5)^{*}$ \\
$\mathrm{Lactate}(\mathrm{mM})$ & $0.84(0.65-1.02)$ & $1.29(1.05-1.53)^{*}$ & $0.90(0.63-1.17)$ \\
$\mathrm{NO}(\mu \mathrm{M})$ & $22.7(18.3-27.1)$ & $19.2(14.4-24.1)$ & $17.8(14.6-21.1)^{*}$
\end{tabular}

Data are presented as means with 95\% confidence intervals. $n=12$, exept for NOx where $n=11$ in hypoxia and recovery. MABP, mean arterial blood pressure; $\mathrm{P}_{a} \mathrm{O}_{2}$, arterial oxygen tension; $\mathrm{P}_{a} \mathrm{CO}_{2}$, arterial $\mathrm{CO}_{2}$ tension; $\mathrm{S}_{a} \mathrm{O}_{2}$, arterial oxygen saturation; Hgb, hemoglobin concentration; NOx, nitrite/nitrate concentration. ${ }^{*} p<0.05$ compared with baseline.

Table 2 | Venous concentrations of catecholamines and endothelial markers before and after hypobaric hypoxia.

\begin{tabular}{lcc}
\hline & Baseline & Recovery \\
\hline Adrenaline $(\mathrm{pg} / \mathrm{ml})$ & $84(38-129)$ & $57(31-82)$ \\
Noradrenaline $(\mathrm{pg} / \mathrm{ml})$ & $199(117-280)$ & $234(134-334)$ \\
Syndecan-1 $(\mathrm{ng} / \mathrm{ml})$ & $22(17-27)$ & $25(19-30)^{*}$ \\
PC $(\%)$ & $76(70-83)$ & $81(74-88)^{*}$ \\
sTM $(\mathrm{ng} / \mathrm{ml})$ & $6.0(5.2-6.8)$ & $6.1(5.3-6.9)$ \\
tPA $(\mathrm{ng} / \mathrm{ml})$ & $3.1(1.5-4.7)$ & $3.3(1.4-5.3)$ \\
PAl-1 $(\mathrm{ng} / \mathrm{ml})$ & $5.7(0.3-11.2)$ & $5.5(-0.6-11.6)$ \\
sCD40L $(\mathrm{pg} / \mathrm{ml})$ & $41(13-68)$ & $33(24-42)$ \\
hcDNA $(\%)$ & $2.6(2.0-3.2)$ & $2.6(2.2-2.9)$
\end{tabular}

Data are presented as means with 95\% confidence limits. $n=11$. PC, protein C; sTM, soluble thrombomodulin; tPA, tissue plasminogen activators; PAl1, plasminogen activator inhibitor 1; sCD40L, soluble CD40 ligand; hcDNA, histone-complexed DNA fragments. ${ }^{*} p<0.02$ compared with baseline.
Measurements with the EndoPAT device could not be obtained in one subject during baseline. Unexpected, the fingertip plethysmograph of the EndoPAT device failed to produce readable tonometry (pulse-signal amplitude) in 5/12 subjects during hypoxia. These subjects were the most affected by the decompression and presented with peripheral vasoconstriction. EndoPAT RHI fell from $1.80(1.52-2.07, n=11)$ at baseline to $1.62(1.28-$ 1.96) during hypoxia $(n=7 ; p=0.11)$ but in the period of post-hypoxia increased significantly to $2.43(1.99-2.86, n=12)$ (Figure 1). At baseline 5/11 of the subjects had a RHI below 1.67 which is denoted as abnormal by the manufacturer of the EndoPAT device. During hypoxia 4/7 of the subjects had RHI values below 1.67; after hypoxia only $1 / 12$ had a RHI below 1.67 . RHI values at baseline and recovery did not correlate with corresponding values of syndecan-1, protein $\mathrm{C}$, or nitrite/nitrate. Nor did RHI during hypoxia correlate with nitrite/nitrate values during hypoxia. Nitrite/nitrate did not correlate with neither syndecan-1 or protein C. No trend was observed regarding degree of degradation of endothelial glycocalyx and reactive hyperemia in relation to exposure time to hypobaric conditions.

\section{DISCUSSION}

The current study suggests that acute, short-term hypobaric hypoxia in humans is associated with minor degradation of the endothelium glycocalyx as reflected by the small increase in syndecan-1. Increased plasma concentrations of protein $\mathrm{C}$ indicate that acute hypobaric hypoxia induced some degree of cellular damage. At the same time, a decrease in venous concentration of nitrite/nitrate was observed. RHI after hypoxic exposure rebounded to higher than baseline levels. The present results are in line with previous studies in isolated, perfused hearts of guinea pigs (Annecke et al., 2011; Becker et al., 2011), and of rats (Ward and Donelly, 1993) showing that hypoxia initiates degradation of the coronary endothelial glycocalyx.

Acute hypoxia has often been shown to impair endothelial function. Earlier studies showed an increased transcapillary escape rate of albumin after $3.5 \mathrm{~h}$ and 2 days at $4500 \mathrm{~m}$ (Parving, 1972; Hansen et al., 1994). Berger et al. (2005) have shown that

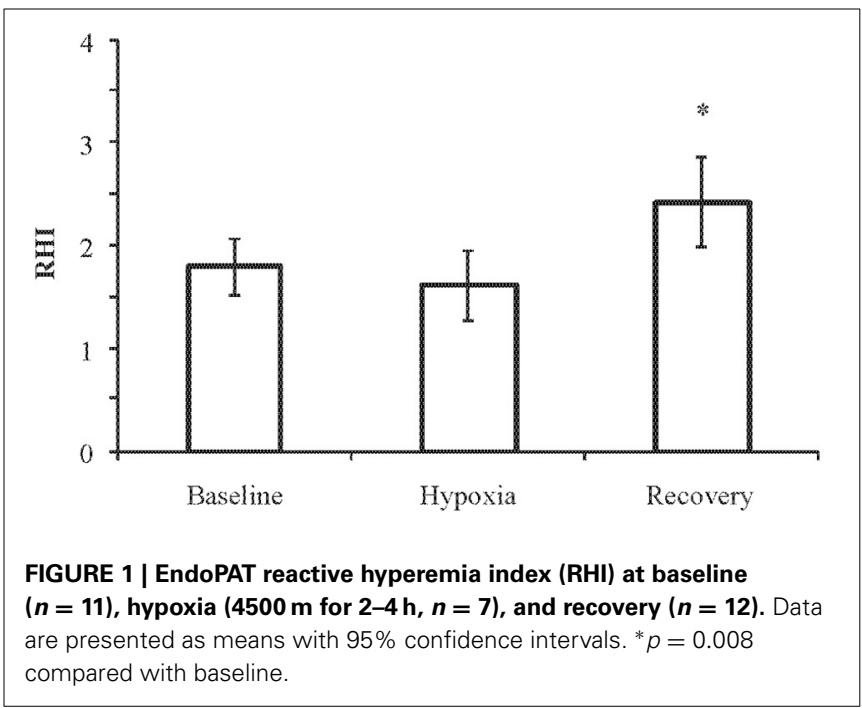


the endothelium dependent vasodilator responsiveness of forearm resistance vessels was blunted by acute normobaric hypoxia in subjects susceptible to HAPE but not in HAPE resistant subjects. Exhaled nitric oxide and pulmonary nitric oxide bioavailability is reduced in HAPE susceptible subjects (Busch et al., 2001; Swenson et al., 2002; Bailey et al., 2010). The present hypoxia induced decrease in systemic venous concentration of nitrite/nitrate is in accordance with previous studies (Bailey et al., 2010; Beall et al., 2012). However, this is associated with an increase in arterial nitrosoproteins and nitric oxide in red blood cells (Bailey et al., 2010). The nitric oxide pathways in hypoxia may both involve down-regulation of endothelial nitric oxide synthase (Beall et al., 2012), and up-regulation of nitric oxide formation from nitrite (Lundberg et al., 2008; David Ho et al., 2012), but exactly how these interactions are related to the RHI signal remains unknown. Interestingly, although hypoxia tended to reduce RHI, it increased above baseline levels in the posthypoxia period, suggesting a beneficial role of hypoxia and its reversal on endothelial integrity. It could be speculated that this response, in part, may be involved in the beneficial effect of hypoxic "conditioning" (Przyklenk, 2013; Thielmann et al., 2013).

Increased levels of catecholamines, syndecan-1 and soluble thrombomodulin in patients with severe trauma, acute myocardial infarction and sepsis are associated with increased mortality (Johansson et al., 2011, 2012, 2013; Ostrowski et al., 2013a,b). In the present study, short-term hypobaric hypoxia did not induce significant increases in circulating catecholamines indicating that an effect on the endothelium from symphathetic outflow was negligible. In agreement with this, only modest increases in syndecan-1 was observed and, furthermore, no change in soluble thrombomodulin levels was found, indicating that no major damage on the endothelial cells was inflicted. We have previously reported that experimental endotoxemia in healthy volunteers receiving a 4 -h $0.5 \mathrm{ng} / \mathrm{kg} / \mathrm{h}$ infusion of E. coli lipopolysaccharide did not result in significant changes of circulating levels of catecholamines, syndecan-1 or soluble thrombomodulin contrary to patients with sepsis (Ostrowski et al., 2013a). Together with the RHI results, this suggests that the hypoxia model used in the present study resulted in a stronger endothelial impact than the LPS model, albeit much weaker than in patients with sepsis. The current level of hypoxia with an arterial oxygen saturation around $80 \%$ is often observed following poisoning with cyanide or carbonmonoxide in smoke inhalation injuries, and in the acute course of several clinical syndromes, i.e., sepsis, trauma, pulmonary thromboembolism and myocardial infarction. We found increased levels of syndecan-1 indicating shedding of the glycocalyx which has been associated with poor outcome in trauma patients (Johansson et al., 2011, 2012), whereas RHI increased as a measure of improved endothelial functionality. The significance of these findings requires further investigation.

We used a non-invasive EndoPat 2000 device for evaluation of peripheral endothelial function by peripheral arterial tonometry (PAT) (Hamburg and Benjamin, 2009; Patvardhan et al., 2010; Hedetoft and Olsen, 2014). The method is based on amplitude tonometry in the finger tip and provides easy and standardized measurements of a RHI value following a 5-min upper arm occlusion. A study in healthy individuals indicated that RHI, in part, depends on flow-mediated release of nitric oxide (Nohria et al., 2006). RHI is decreased in the presence of cardiovascular risk factors (Bonetti et al., 2004; Hamburg et al., 2008, 2011), and measurements of RHI may be used to predict risk of adverse cardiovascular events after surgery (Gokce et al., 2002) and acute coronary syndrome (Rubinshtein et al., 2010). Although patterns of abnormalities measured by PAT follow the same trend as that measured by brachial artery ultrasound in response to flow-mediated vasodilatation (Kuvin et al., 2003), it has become clear that the methods are not interchangeable (Lind et al., 2005; Dhingsa et al., 2008; Hamburg et al., 2011). Endothelial function in the brachial conduit artery and the smaller resistance vessels in the finger are governed by different mechanisms, and the two methods provide distinct information about endothelial function (Lind et al., 2005; Dhingsa et al., 2008; Hamburg et al., 2011). Nonetheless, the use of PAT may provide new ways to study the interaction between hypoxia and peripheral flow dynamics.

\section{LIMITATIONS}

The time course in hypoxia plays an important role. Whereas short-term hypoxia may result in vasoconstriction in pulmonary and renal vessels and vasodilation in skeletal muscle, alterations in glycocalyx may require longer time (Pries et al., 2000; Vink et al., 2000; Nieuwdorp et al., 2006; Chappell et al., 2010; Johansson et al., 2011; Ostrowski et al., 2013a,b). Thus, the present use of only $2-4 \mathrm{~h}$ of hypoxia may have been too short to reveal the potential effect on the glycocalyx. In addition, the failure of obtaining fingertip plethysmographic signals with the EndoPAT device during hypoxia unfortunately weakened the study. Thus, the study would have benefited from inclusion of other measurements like flow-mediated vasodilatation in the brachial artery and nitric oxide bioavailability in red blood cells and exhaled air. Moreover, assessment of biochemical markers of glycocalyx degradation are indirect methods that are not comparable to direct investigation of the glycocalyx by electron-microscopy or confocal microscopy.

\section{CONCLUDING REMARKS}

The increase in syndecan-1 and protein $C$ suggests that acute hypobaric hypoxia produces minor degree of glycocalyx degradation and overall cellular damage. After hypoxia RHI rebounded to higher than baseline levels suggesting improved endothelial functionality.

\section{AUTHOR CONTRIBUTIONS}

Pär I. JohanssonĆ Anita Bergström and Niels J. AachmannAndersen: Principal contribution to design of the work acquisition analysis and interpretation of data. Principal drafting revising and (final) approval of the manuscript Accountable for all aspects of the work. Martin A. S. Meyer, Sisse R. Ostrowski and Nikolai B. Nordsborg: Important contribution to design of the work, analysis, and interpretation of data. Contributed to drafting, revising, and (final) approval of the manuscript. Accountable for all aspects of the work. Niels V. Olsen: Principal contribution to design of the work, analysis, and (final) approval of the manuscript. Accountable for all aspects of the work. 


\section{ACKNOWLEDGMENT}

The authors thank biotechnician Birgit Heine Hansen for skillful laboratory assistance.

\section{REFERENCES}

Annecke, T., Fischer, J., Hartmann, H., Tschoep, J., Rehm, M., Conzen, P., et al. (2011). Shedding of the coronary endothelial glycocalyx: effects of hypoxia/reoxygenation vs ischaemia/reperfusion. Br. J. Anaesth. 107, 679-686. doi: 10.1093/bja/aer269

Bailey, D. M., Dehnert, C., Luks, A. M., Menold, E., Castell, C., Schendler, G., et al. (2010). High-altitude pulmonary hypertension is associated with a free radicalmediated reduction in pulmonary nitric oxide bioavailability. J. Physiol. 588, 4837-4847. doi: 10.1113/jphysiol.2010.194704

Bärtsch, P., Mairbäurl, H., Maggiorini, M., and Swenson, E. R. (2005). Physiological aspects of high-altitude pulmonary edema. J. Appl. Physiol. 98, 1101-1110. doi: 10.1152/japplphysiol.01167.2004

Beall, C. M., Laskowski, D., and Erzurum, S. C. (2012). Nitric oxide in adaptation to altitude. Free Radic. Biol. Med. 52, 1123-1134. doi: 10.1016/j.freeradbiomed.2011.12.028

Becker, B. F., Fischer, J., Hartmann, H., Chen, C. C., Sommerhoff, C. P., Tschoep, J., et al. (2011). Inosine, not adenosine, initiates endothelial glycocalyx degradation in cardiac ischemia and hypoxia. Nucleosides Nucleotides Nucleic Acids 30, 1161-1167. doi: 10.1080/15257770.2011.605089

Berger, M. M., Hesse, C., Dehnert, C., Siedler, H., Kleinbongard, P., Bardenheuer, H. J., et al. (2005). Hypoxia impairs systemic endothelial function in individuals prone to high-altitude pulmonary edema. Am. J. Respir. Crit. Care Med. 172, 763-767. doi: 10.1164/rccm.200504-654OC

Bonetti, P. O., Pumper, G. M., Higano, S. T., Holmes, D. R. Jr., Kuvin, J. T., and Lerman, A. (2004). Noninvasive identification of patients with early coronary atherosclerosis by assessment of digital reactive hyperemia. J. Am. Coll. Cardiol. 44, 2137-2141. doi: 10.1016/j.jacc.2004.08.062

Busch, T., Bärtsch, P., Pappert, D., Grünig, E., Hildebrandt, W., Elser, H., et al. (2001). Hypoxia decreases exhaled nitric oxide in mountaineers susceptible to high-altitude pulmonary edema. Am. J. Respir. Crit. Care Med. 163, 368-73. doi: 10.1164/ajrccm.163.2.2001134

Chappell, D., Dörfler, N., Jacob, M., Rehm, M., Welsch, U., Conzen, P., et al. (2010). Glycocalyx protection reduces leukocyte adhesion after ischemia/reperfusion. Shock 34, 133-139. doi: 10.1097/SHK.0b013e3181cdc363

David Ho, J. J., Man, H. S. J., and Marsden, P. A. (2012). Nitric oxide signaling in hypoxia. J. Mol. Med. 90, 217-231. doi: 10.1007/s00109-012-0880-5

Dhingsa, M., Sommerlad, S. M., DeVan, A. E., Barnes, J. N., Sugawara, J., Ley, O., et al. (2008). Interrelationships among noninvasive measures of postischemic macro-and microvascular reactivity. J. Appl. Physiol. 105, 427-432. doi: 10.1152/japplphysiol.90431.2008

Faizi, A. K., Kornmo, D. W., and Agewall, S. (2009). Evaluation of endothelial function using finger plethysmography. Clin. Physiol. Funct. Imaging 29, 372-375. doi: 10.1111/j.1475-097X.2009.00882.x

Gokce, N., Keaney, J. F. Jr., Hunter, L. M., Watkins, M. T., Menzoian, J. O., and Vita, J. A. (2002). Risk stratification for postoperative cardiovascular events via noninvasive assessment of endothelial function: a prospective study. Circulation 105, 1567-1572. doi: 10.1161/01.CIR.0000012543.55874.47

Gonzalez, N. C., and Wood, J. G. (2010). Alveolar hypoxia-induced systemic inflammation: what low PO2 does and does not. Adv. Exp. Med. Biol. 662, 27-32. doi: 10.1007/978-1-4419-1241-1_3

Hamburg, N. M., and Benjamin, E. J. (2009). Assessment of endothelial function using digital pulse amplitude tonometry. Trends Cardiovasc. Med. 19, 6-11. doi: 10.1016/j.tcm.2009.03.001

Hamburg, N. M., Keyes, M. J., Larson, M. G., Vasan, R. S., Schnabel, R., Pryde, M. M., et al. (2008). Cross-sectional relations of digital vascular function to cardiovascular risk factors in the Framingham Heart Study. Circulation 117, 2467-2474. doi: 10.1161/CIRCULATIONAHA.107.748574

Hamburg, N. M., Palmisano, J., Larson, M. G., Sullivan, L. M., Lehman, B. T., Vasan, R. S., et al. (2011). Relation of brachial and digital measures of vascular function in the community: the Framingham heart study. Hypertension 57, 390-396. doi: 10.1161/HYPERTENSIONAHA.110.160812

Hansen, J. M., Olsen, N. V., Feldt-Rasmussen, B., Kanstrup, I. L., Déchaux, M., Dubray, C., et al. (1994). Albuminuria and overall capillary permeability of albumin in acute altitude hypoxia. J. Appl. Physiol. 76, 1922-1927.
Hedetoft, M., and Olsen, N. V. (2014). Evaluation of endothelial function by peripheral arterial tonometry and relation with the nitric oxide pathway. Nitric Oxide 42C, 1-8. doi: 10.1016/j.niox.2014.07.003

Johansson, P. I., Sørensen, A. M., Perner, A., Welling, K. L., Wanscher, M., Larsen, C. F., et al. (2012). High sCD40L levels early after trauma are associated with enhanced shock, sympathoadrenal activation, tissue and endothelial damage, coagulopathy and mortality. J. Thromb. Haemost. 10, 207-216. doi: 10.1111/j.1538-7836.2011.04589.x

Johansson, P. I., Stensballe, J., Rasmussen, L. S., and Ostrowski, S. R. (2011). A high admission syndecan-1 level, a marker of endothelial glycocalyx degradation, is associated with inflammation, protein C depletion, fibrinolysis, and increased mortality in trauma patients. Ann. Surg. 254, 194-200. doi: 10.1097/SLA.0b013e318226113d

Johansson, P. I., Windeløv, N. A., Rasmussen, L. S., Sørensen, A. M., and Ostrowski, S. R. (2013). Blood levels of histone-complexed DNA fragments are associated with coagulopathy, inflammation and endothelial damage early after trauma. J. Emerg. Trauma Shock 6, 171-175. doi: 10.4103/0974-2700.115327

Kuvin, J. T., Patel, A. R., Sliney, K. A., Pandian, N. G., Sheffy, J., Schnall, R. P., et al. (2003). Assessment of peripheral vascular endothelial function with finger arterial pulse wave amplitude. Am. Heart J. 146, 168-74. doi: 10.1016/S00028703(03)00094-2

Lind, L., Fors, N., Hall, J., Marttala, K., and Stenborg, A. (2005). A comparison of three different methods to evaluate endothelium-dependent vasodilation in the elderly: the prospective investigation of the vasculature in uppsala seniors (PIVUS) study. Arterioscler. Thromb. Vasc. Biol. 25, 2368-2375. doi: 10.1161/01.ATV.0000184769.22061.da

Lundberg, J. O., Weitzberg, E., and Gladwin, M. T. (2008). The nitrate-nitritenitric oxide pathway in physiology and therapeutics. Nat. Rev. Drug Discov. 7, 156-167. doi: $10.1038 / \mathrm{nrd} 2466$

Nieuwdorp, M., van Haeften, T. W., Gouverneur, M. C., Mooij, H. L., van Lieshout, M. H., Levi, M., et al. (2006). Loss of endothelial glycocalyx during acute hyperglycemia coincides with endothelial dysfunction and coagulation activation in vivo. Diabetes 55, 480-486. doi: 10.2337/diabetes.55.02.06.db05-1103

Nohria, A., Gerhard-Herman, M., Creager, M. A., Hurley, S., Mitra, D., and Ganz, P. (2006). Role of nitric oxide in the regulation of digital pulse volume amplitude in humans. J. Appl. Physiol. 101, 545-548. doi: 10.1152/japplphysiol.01285.2005

Ostrowski, S. R., Berg, R. M., Windeløv, N. A., Meyer, M. A., Plovsing, R. R., Møller, K., et al. (2013a). Discrepant fibrinolytic response in plasma and whole blood during experimental endotoxemia in healthy volunteers. PLoS ONE 8:e59368. doi: 10.1371 /journal.pone.0059368

Ostrowski, S. R., Pedersen, S. H., Jensen, J. S., Mogelvang, R., and Johansson, P. I. (2013b). Acute myocardial infarction is associated with endothelial glycocalyx and cell damage and a parallel increase in circulating catecholamines. Crit. Care 17, R32. doi: $10.1186 / \mathrm{cc} 12532$

Parving, H. H. (1972). The effect of hypoxia and carbon monoxide exposure on plasma volume and capillary permeability to albumin. Scand. J. Clin. Lab. Invest. 30, 49-56. doi: 10.3109/00365517209081089

Patvardhan, E. A., Heffernan, K. S., Ruan, J. M., Soffler, M. I., Karas, R. H., and Kuvin, J. T. (2010). Assessment of vascular endothelial function with peripheral arterial tonometry: information at your fingertips? Cardiol. Rev. 18, 20-28. doi: 10.1097/CRD.0b013e3181c46a15

Pries, A. R., Secomb, T. W., and Gaehtgens, P. (2000). The endothelial surface layer. Pflugers Arch. 440, 653-666. doi: 10.1007/s004240000307

Przyklenk, K. (2013). Reduction of myocardial infarct size with ischemic "conditioning": physiologic and technical considerations. Anesth. Analg. 117, 891-901. doi: 10.1213/ANE.0b013e318294fc63

Rubinshtein, R., Kuvin, J. T., Soffler, M., Lennon, R. J., Lavi, S., Nelson, R. E., et al. (2010). Assessment of endothelial function by non-invasive peripheral arterial tonometry predicts late cardiovascular adverse events. Eur. Heart J. 31, 1142-1148. doi: 10.1093/eurheartj/ehq010

Schneider, J. C., Blazy, I., Déchaux, M., Rabier, D., Mason, N. P., and Richalet, J. P. (2001). Response of nitric oxide pathway to L-arginine infusion at the altitude of 4,350 m. Eur. Respir. J. 18, 286-292. doi: 10.1183/09031936.01.00073401

Swenson, E. R., Maggiorini, M., Mongovin, S., Gibbs, J. S., Greve, I., Mairbäurl, H., et al. (2002). Pathogenesis of high-altitude pulmonary edema: inflammation is not an etiologic factor. JAMA 287, 2228-2235. doi: 10.1001/jama.287.17.2228

Ten, V. S., and Pinsky, D. J. (2002). Endothelial response to hypoxia: physiologic adaptation and pathologic dysfunction. Curr. Opin. Crit. Care 8, 242-250. doi: 10.1097/00075198-200206000-00008 
Thielmann, M., Kottenberg, E., Kleinbongard, P., Wendt, D., Gedik, N., Pasa, S., et al. (2013). Cardioprotective and prognostic effects of remote iscaemic preconditioning in patients undergoing coronary artery bypass surgery. Lancet 382, 597-604. doi: 10.1016/S0140-6736(13)61450-6

Vink, H., Constantinescu, A. A., and Spaan, J. A. (2000). Oxidized lipoproteins degrade the endothelial surface layer: implications for plateletendothelial cell adhesion. Circulation 101, 1500-1502. doi: 10.1161/01.CIR.101. 13.1500

Ward, B. J., and Donelly, J. L. (1993). Hypoxia induced disruption of the cardiac endothelial glycocalyx: implications for capillary permeability. Cardiovasc. Res. 27, 384-389. doi: 10.1093/cvr/27.3.384

Conflict of Interest Statement: The authors declare that the research was conducted in the absence of any commercial or financial relationships that could be construed as a potential conflict of interest.
Received: 17 September 2014; accepted: 07 November 2014; published online: 24 November 2014.

Citation: Johansson PI, Bergström A, Aachmann-Andersen NJ, Meyer MAS, Ostrowski SR, Nordsborg NB and Olsen NV (2014) Effect of acute hypobaric hypoxia on the endothelial glycocalyx and digital reactive hyperemia in humans. Front. Physiol. 5:459. doi: 10.3389/fphys.2014.00459

This article was submitted to Clinical and Translational Physiology, a section of the journal Frontiers in Physiology.

Copyright (C) 2014 Johansson, Bergström, Aachmann-Andersen, Meyer, Ostrowski, Nordsborg and Olsen. This is an open-access article distributed under the terms of the Creative Commons Attribution License (CC BY). The use, distribution or reproduction in other forums is permitted, provided the original author(s) or licensor are credited and that the original publication in this journal is cited, in accordance with accepted academic practice. No use, distribution or reproduction is permitted which does not comply with these terms. 